\title{
El principio de objetividad en el Derecho Administrativo francés
}

\author{
Benoît Delaunay \\ Catedrático en la Facultad de Derecho \\ Profesor de Derecho Público en la Universidad de París Descartes \\ Delaunay.benoit@netcourrier.com
}

\begin{abstract}
Resumen
En derecho administrativo francés, el principio de objetividad casi no existe en sí mismo, sino bajo diferentes apellidos: el principio de igualdad, el principio de imparcialidad, el principio de neutralidad, el principio de laicidad. Esta situación plantea el problema del valor jurídico que tiene el principio de objetividad. Pero, más allá, hay que poner de manifiesto las diferentes apariciones de la objetividad-que son numerosas-tanto en el estatuto de los funcionarios como en la acción administrativa cotidiana. Bajo esta perspectiva se construye el principio de objetividad a través de la elaboración de una deontología administrativa y de la sanción de la ilegalidad y de la responsabilidad en caso de falta de objetividad.
\end{abstract}

Palabras clave

Neutralidad, Imparcialidad, Igualdad, Laicidad, Funcionarios, Acción administrativa.

\section{The principle of ojectivity in French administrative law}

\begin{abstract}
In French administrative law, the principle of objectivity in itself hardly exists but does so under different names: the principle of equality, the principle of impartiality, the principle of neutrality, the principle of laïcité. This situation raises the problem of the legal value of the principle of objectivity. But, beyond this, we should highlight the different appearances of objectivity - which are many - both in the civil servants' statutes and in everyday administrative action. In this light, the principle of objectivity is built through the formulation of an administrative deontology, the sanctioning of illegality and the liability in the event of lack of objectivity.
\end{abstract}

Key words

Neutrality, Impartiality, Equality, Laicism, Civil servants, Administrative Action. 
Para adentrarnos en materia de forma provocadora, pero sin faltar a la verdad formal, podríamos afirmar que el principio de objetividad no existe en el derecho administrativo francés. Para justificar dicha afirmación, apuntaríamos que ni los jueces ni la doctrina lo han reconocido nunca y pondríamos de manifiesto que los repertorios de sentencias judiciales, los manuales de la administración pública, de la ciencia administrativa o incluso del derecho administrativo general permanecen implacablemente mudos con respecto a esta cuestión, sin que conste mención alguna de este término en sus índices ni en sus tablas de contenidos. Se podría abordar fácilmente el tema de esta manera, si bien de forma traicionera si negamos la existencia de este principio en el derecho administrativo francés.

Esta cómoda escapatoria constituiría una doble equivocación.

Por una parte, a pesar de todo, una búsqueda sistemática nos hace dar con unas conclusiones pronunciadas ante el Consejo de Estado con la prudente pluma de dos comisarios del Gobierno que desvelan un principio de objetividad, elevado al rango de principio general de derecho, con toda claridad. $Y$ para no quedarnos con un solo ejemplo, ¿no percibe el presidente Labetoulle una "regla, con valor de principio general de derecho, según la cual la objetividad de un agente o de un auxiliar de la administración no debe dar lugar a sospechas"'? Además, parece que la búsqueda de la objetividad puede convertirse en una verdadera obligación del servicio público, tal y como se estipula para la enseñanza superior en el artículo L. 141-6 del Código de la Educación. Quedaría entonces garantizada por la protección particular de la independencia de docentes e investigadores, haciendo gala de la aplicación de las imposiciones de "los principios de tolerancia y de objetividad".

Por otra parte, resulta evidente que el principio de objetividad se manifiesta materialmente bajo otras denominaciones: principio de neutralidad del servicio público y de los funcionarios, principio de laicidad, principio de imparcialidad de los agentes públicos y de la acción administrativa. De hecho, podemos incluso ser testigos de sustituciones, confusión y equivalencias entre todos estos conceptos que, cual muñecas rusas Matrioskas, se entremezclan, encajan, se da preferencia a unos u a otros y se descartan según qué épocas, de tal manera que se puede llegar a perder de vista la objetividad. La neutralidad expresa una voluntad de abstención y una preocupación por la imparcialidad. La imparcialidad, por su parte, designa la calidad de todo aquél que no se compromete ni toma partido por una parte o por la otra. Resulta evidente que, a pesar de presentar matices distintos, estos términos han de tomarse

1 D. Labetoulle, concl. sobre el CE del 8 de diciembre de 1982, Marsac et autres JCP 1983, 20016. Véase, anteriormemente, G. Braibant, concl. sobre el CE Secc. del 13 de noviembre de 1970, Moreau et autres Rec. 661.

2 Citaremos el caso del Instituto nacional de consumo que tiene que poder expresar sobre los productos que controla "todas las apreciaciones o valoraciones, independientemente de lo duras que puedan llegar a ser, siempre que sean objetivas y que no respondan a ninguna intención de denigración 
por equivalentes en esta fase del estudio, en consonancia, además, con las prácticas administrativas y jurisdiccionales. Por ejemplo, en el célebre caso Barel$^{3}$, relativo a las oposiciones de la administración, el juez no se apoya en la parcialidad del secretario de Estado, sino en el incumplimiento del principio de igual acceso al empleo público. Sin embargo, en un caso similar, el de Clohars-Carnoët ${ }^{4}$, fundamenta su fallo en la parcialidad del alcalde en lugar de en el incumplimiento del principio de igualdad.

Esta dificultad nos conduce directamente a la cuestión del estatus del principio de objetividad. De lege lata, dicho principio no es en realidad tal principio, sino que se presenta más como el derivado de varios principios parecidos en vez de como un principio autónomo e independiente. De hecho, cuesta trabajo encontrar sentencias judiciales en donde se determine el valor jurídico del principio de objetividad con la misma precisión que para los principios de igualdad, de neutralidad y de imparcialidad $^{5}$. Por ejemplo, a pesar de que la imparcialidad se ha podido reconocer como principio general de derecho, es decir, un principio de valor suprarreglamentario e infralegislativo6 -el propio Consejo de Estado se basa en "la obligación general de imparcialidad, que incumbe a todos los organismos administrativos" -, solamente se confiere este valor a la objetividad de forma indirecta. De igual modo, el debate doctrinal para saber si el principio de neutralidad del servicio público es un derivado del principio de igualdad o si, por el contrario, ha adquirido una autonomía propia que le permita elevarse al rango de principio, no resulta decisivo: corolario del principio de igualdad en un principio, luego "principio fundamental que rige el servicio público", la neutralidad, sea cual sea la hipótesis tomada en consideración, está muy vinculada a la objetividad. Por este motivo consideraremos secundaria la cuestión del valor jurídico del principio de objetividad en el derecho administrativo francés -en nuestra opinión zanjada por las conclusiones de los comisarios de gobierno anteriormente citados- con el objeto de privilegiar un enfoque en términos de contenido y de sanción del principio.

3 CE As. del 28 de mayo de 1954, Barel, RDP 1954, p. 509.

4 CE Secc. del 9 de noviembre de 1966, D. 1967, p. 92, concl. G. Braibant.

5 CC del 28 de julio de 1989.

6 En este sentido, véase B. Jeanneau, Les principes généraux du droit dans la jurisprudence administrative, Sirey, 1954, p. 90 ; M. Waline, nota sobre el CE del 10 de julio de 1963, Hôpital-Hospice Georges Renon, RDP 1964, p. 439 ; G. Vedel y P. Delvolvé, Droit administratif, p. 470. Para una apreciación con más matices, véase M. Degoffe, “L'impartialité de la décision administrative”, RFDA 1998, p. 711.

7 CE del 1 de abril de 1998, lguacel et Comets, Rec. tab. 981; Cahiers fonction publique, junio de 1998, p. 27.

En este caso, el Consejo de Estado debía responder a la cuestión de si un funcionario miembro de una comisión administrativa paritaria podía o no participar en la misma cuando se hubiese realizado una petición de revisión de sus propias notas. La respuesta parecía claramente negativa, si bien en ningún texto se había previsto esta norma de sensatez. El Consejo de Estado, apelando al principio de imparcialidad, prohibió en lo sucesivo la participación de los miembros de las comisiones administrativas paritarias en las deliberaciones relativas a su situación personal. Anteriormente, véase el CE Sec. del 20 de junio de 1958, Louis, Rec. 368.

8 CC n. ${ }^{\circ}$ 96-380 DC, 23 de julio de 1996, Loi relative à l'entreprise nationale France Téléom, Rec. 107. 
La objetividad designa la calidad de una persona "cuyos juicios objetivos, imparciales, no se ven alterados por ninguna preferencia subjetiva" 9 . Vemos, en el lenguaje informal, que la objetividad se construye en negativo de la subjetividad. La dificultad aumenta si nos interrogamos sobre los autores de la objetividad, los que deben dar prueba de objetividad: ¿se trata de agentes de la administración o de la propia administración? En otros términos, ¿es la objetividad un requisito de obligado cumplimiento únicamente para la función pública o se aplica al conjunto de la acción administrativa a través de la administración percibida como una institución? No cabe la menor duda de que ambos aspectos del tema están íntimamente ligados, dado que los funcionarios y la administración constituyen a menudo una única realidad -tal y como instruye el derecho de la responsabilidad-, si bien a partir de ahora cabe señalar que a veces nos veremos obligados a discernir entre la situación de los actores, por un lado, y la de la acción, por otro.

Los actores han percibido la dificultad resultante tratando la cuestión de la imparcialidad administrativa: "Podemos considerar decepcionante el análisis de la parcialidad relativa al agente. Una queja invocada a menudo, y mantenida en raras ocasiones, entre otras cuestiones por el recelo instintivo del administrado y la objetividad del funcionario. Aunque también por la conducta de unos jueces con exceso de poder, quienes juzgan el acto sin pararse a considerar, en principio, las intenciones del agente. El otro límite se basa en que la jurisprudencia se fundamenta en el siguiente axioma: el agente puede fallar eventualmente, pero la organización administrativa no tiene segundas intenciones. Sin duda alguna, esto explica en gran parte por qué los jueces administrativos no consagran un principio general en virtud del cual un funcionario no pueda participar en la adopción de una decisión sobre un asunto que haya conocido previamente o en el que tenga algún interés”"10.

Podemos observar que los jueces son vitales para el reconocimiento de un principio de objetividad debido a la escasez de referencias textuales al principio de objetividad o a los principios que lo sustentan. No debemos olvidar que los propios jueces han de ser objetivos en su profesión diaria impartiendo justicia. No obstante, lo que comúnmente denominamos imparcialidad de los jueces no será objeto de estudio en el presente documento, dado que esta cuestión es merecedora de todo un estudio ${ }^{11}$ para ella sola que completa en la actualidad la adopción reciente de una guía deontológica destinada a los magistrados. Además, la cuestión de la imparcialidad de la jurisdicción administrativa se ve perturbada hoy en día por la influencia creciente del Tribunal europeo y, en particular, de la teoría de la apariencia. De hecho, para ser efectiva, la imparcialidad debe dar total apariencia de serlo. Por ello el Tribunal no se limita a evitar todo riesgo de juicio previo en cada etapa del procedimiento, sino que va más allá y excluye toda impresión de prejuicio que pudiese nacer en la mente del

9 Littré, Diccionario de la lengua francesa.

10 M. Degoffe, préc. p. 718.

11 Para desarrollar esta cuestión, véase J.-G. Sorbara, L'impartialité du juge administratif, tésis, Pa-

284 rís II, 2005; B. Delaunay, "L'impartialité du juge financier”, RFDA 2008, p. 381. 
justiciable. Las sanciones solamente se podrán imponer en condiciones que cumplan con los requisitos del principio de imparcialidad, "recordado" por el artículo $6 \S 1$ del Convenio europeo de derechos humanos ${ }^{12}$.

Por tanto, en los planteamientos sucesivos deberemos tratar principalmente la objetividad de la administración, es decir, desvinculada de la cuestión de los jueces administrativos, lo que en realidad resulta más sencillo debido a la separación más que secular de la administración y “sus" jueces. De que la administración se esfuerza por asentar su autoridad sobre el respeto de la objetividad no cabe la menor duda; no obstante, convendrá medir la efectividad de este postulado, buscar manifestaciones de lo que los profesores Chevallier y Lochak escribieron desde finales de los años 70: "Por esencia, la administración es neutra y objetiva: escapa a las jerarquizaciones sociales, a los antagonismos de clases, siendo un árbitro imparcial"13.

Podremos realizar dicha medida analizando las manifestaciones del principio de objetividad en el derecho administrativo francés (I) y posteriormente indagando sobre la creación de este principio (II).

\section{LAS MANIFESTACIONES DEL PRINCIPIO DE OBJETIVIDAD EN EL DERECHO ADMINISTRATIVO FRANCÉS}

El requisito de objetividad en el derecho administrativo francés es aplicable tanto a los agentes de la administración como, de forma aparentemente más abstracta, a la propia acción administrativa.

\section{El principio de objetividad de los agentes de la administración}

La objetividad es una obligación deontológica que se impone a los agentes públicos. Guy Braibant ${ }^{14}$ y Daniel Labetoulle ${ }^{15}$ son los dos únicos autores que han identificado la existencia de una obligación de objetividad para los funcionarios, erigida en principio general de derecho. Esta situación se explica por el hecho de que se ha hecho uso en mayor medida de otros dos principios, anclados más sólidamente en el derecho administrativo francés: la imparcialidad y la neutralidad. Sin embargo, son numerosos los vínculos con la objetividad que de ellos emanan.

12 CE As. del 3 de diciembre de 1999, Didier, Rec. 399; AJDA 2000, p. 126, chron. M. Guyomar y P. Colin, JCP 2000, I, 251, obs. C. Boiteau.

13 J. Chevallier y D. Lochak, Science administrative, 1978, n. 1113. 661.

14 G. Braibant, conclusiones sobre el CE Sec. del 13 de noviembre de 1970, Moreau et autres, Rec. 20016.

15 D. Labetoulle, conclusiones sobre el CE del 8 de diciembre de 1982, Marsac et autres, JCP 1983, 


\subsection{La objetividad garantizada por la imparcialidad de los agentes públicos}

La obligación de imparcialidad ${ }^{16}$ no está prevista expresamente en el estatuto general de los funcionarios. No obstante, un estudio sistemático de la jurisprudencia revela que se puede alegar una falta de imparcialidad de los funcionarios en cuatro supuestos principales.

En primer lugar, los funcionarios pueden tener un interés personal en determinadas cuestiones ${ }^{17}$, si bien deben actuar en aras del interés general y no de intereses privados (aunque puede ocurrir que ambos se superpongan ${ }^{18}$ ). Por este motivo, los jueces deberán examinar con detenimiento los intereses que pueden albergar los consejeros municipales en el transcurso de una determinada deliberación ${ }^{19}$. De igual modo, a los miembros de las autoridades administrativas independientes se les prohíbe generalmente participar en deliberaciones en las que tengan algún tipo de interés que pueda afectar a su independencia o su imparcialidad. Lo mismo es aplicable a la Autoridad de seguridad nuclear ${ }^{20}$, a la Autoridad de la competencia ${ }^{21} \mathrm{o}$ a la Agencia nacional de lucha contra el dopaje ${ }^{22}$. En fin, se considera que un agente que cuente con una determinada autoridad administrativa no debería utilizar sus prerrogativas para favorecer o perjudicar a un administrado: se sancionará ${ }^{23}$ al verificador de pesos y medidas que incite a los comerciantes a confiar la reparación de su material a la competencia del demandante.

En segundo lugar, puede ocurrir que un funcionario albergue una animosidad personal contra el destinatario de un determinado acto $^{24}$. Así, resulta comprensible que un juez anule el traslado de una agente depositaria de archivos nacionales motivado por la animosidad que alberga el director general contra el marido de dicha agente ${ }^{25}$.

En tercer lugar, se considera que un funcionario no haría gala de imparcialidad si adopta una postura pública particular y anterior a la resolución. Sin embargo, la distinción entre este supuesto y el precedente se antoja a veces complicada, tal y como ilustra el caso en el que un miembro de la comisión de especialistas desatiende su

16 El principio de imparcialidad conlleva dos aspectos: implica que los miembros del organismo en cuestión no puedan tener segundas intenciones personales (imparcialidad subjetiva) y exige que no se ponga en duda la independencia del organismo (imparcialidad objetiva).

17 CE del 4 de marzo de 1964, Borderie, Rec. 157.

18 D. Truchet, Les fonctions de la notion d'intérêt général dans la jurisprudence du Conseil d'Etat, LGDJ, 1977, p. 308. Véase, por ejemplo, el CE del 29 de junio de 1951, Syndicat de la raffinerie de soufre française, Rec. 377 ; S. 1952, III, 33, concl. Barbet ; D. 1951, J. 661, nota de M. Waline.

19 CE del 12 de febrero de 1986, Commune d'Ota, Rec. 39.

20 Artículo 13 de la ley del 13 de junio de 2006.

21 Artículo L.461-2 del código de comercio.

22 Artículo R. 232-24 del código del deporte.

23 CE del 4 de enero de 1936, Trolez, Rec. 17.

24 CE del 13 de noviembre de 1989, Ministre de l'Education nationale c. Navarro, req. n. ${ }^{\circ} 73836$.

28625 CE del 31 de octubre de 1973, Dame Gille, Rec. 605. 
obligación de imparcialidad cuando, en su informe sobre la candidatura de un solicitante cualificado por el Consejo nacional de universidades, realiza valoraciones polémicas y expresa discrepancias profesionales y observaciones críticas sobre las condiciones de la creación por parte del interesado del laboratorio que dirige, motivo por el que se anuló la decisión del Consejo de administración de la universidad de no proponer nombramiento alguno para el puesto de profesor de universidad ${ }^{26}$.

En cuarto y último lugar, la falta de discernimiento o de valoración se considera incontestablemente un signo de parcialidad ${ }^{27}$. Por este motivo se le puede negar el acceso a la magistratura a una persona de la que varias autoridades, entre ellas la Cancillería, hubiesen señalado, en el transcurso de los años precedentes, que "denotaba una ausencia de medida, de juicio y de objetividad incompatibles con el ejercicio de funciones judiciales" ${ }^{28}$. Además, las convicciones personales, aunque respetables, no son motivo legal de decisión y pueden constituir un error de derecho. En esta línea, un agente de la ANPE no puede negarse a entregar una ayuda de fomento a un desempleado que vaya a crear su empresa si se cumplen los criterios de creación, aun cuando la empresa creada sea contraria a sus convicciones -por ejemplo un sex $s h o p^{29}$. En un registro totalmente distinto, François Maspero escribió que su padre había "votado contra la candidatura al Colegio de Francia de X, historiador especialista del norte de África, bajo el pretexto de que le había enviado su carta en un papel con el encabezado ministerial del gabinete de Léon Blum, del que formaba parte" ${ }^{30}$.

\subsection{La objetividad garantizada por la neutralidad de los agentes públicos}

Completando la exigencia de imparcialidad de los agentes públicos, la jurisprudencia se ha referido expresamente al "deber de estricta neutralidad al que están obligados todos los agentes que colaboren en un servicio público" ${ }^{31}$. Naturalmente, dicha obligación solamente puede prevalecer durante el servicio, dado que fuera de éste los agentes son libres de manifestar su opinión, siempre que no falten a la lealtad a la que se deben. Del principio de neutralidad se deriva que los agentes no deban manifestar sus opiniones políticas ni religiosas: se puede hablar de "neutralización de las convicciones"32.

En materia religiosa, la neutralidad del agente es una consecuencia del principio de laicidad de los servicios públicos. Se ha considerado claramente que el respeto de

26 CE del 28 de abril de 2004, Eric B., req. n. ${ }^{\circ} 257385$.

27 CE del 21 de febrero de 1994, Bourges, req. n. 124117.

28 CE del 25 de noviembre de 1987, Bertin, Rec. 809.

29 CE del 8 septiembre de 1995 , Lang, req. n. 155287.

30 F. Maspero, Les abeilles et les guêpes, Seuil, 2002, p. 99. Comentado por Ch. Vigouroux, Déontologie des fonctions publiques, p. 178.

31 CE del 3 mayo de 1950, Dlle Jamet, Rec. 247; S. 1951, III, 73. Véase, anteriormente, CE del 25 de julio de 1939, Slle Beis, Rec. 524.

32 Ch. Eisenmann, prefacio a C. Fourier, La liberté d'opinion du fonctionnaire, LGDJ 1957, p. VIII. 
la laicidad del servicio público es de obligado cumplimiento para todos los agentes públicos ${ }^{33}$, sin distinguir entre funciones, tal y como lo ha enunciado el Consejo en su dictamen Demoiselle Marteaux ${ }^{34}$. En el marco de los servicios públicos, los agentes no pueden ni expresar ni manifestar su fe: “El principio de laicidad obstaculiza, en el marco del servicio público, su derecho a manifestar sus creencias religiosas". Siguiendo esta línea de conducta, los jueces administrativos han juzgado, por ejemplo, que el uso por parte de un agente del correo electrónico de su entidad de docencia en beneficio de la Asociación para la unificación del cristianismo mundial constituye un doble incumplimiento: en primer lugar, del principio de laicidad y, en segundo lugar, de la obligación de neutralidad ${ }^{35}$. Por el contrario, el principio de neutralidad-laicidad no implica que a un agente público no se le pueda conceder una autorización de ausencia por fiesta religiosa de su confesión ${ }^{36}$.

También se ha planteado la cuestión más específica de si un agente público puede o no llevar puesto algún signo religioso. Se ha considerado que el funcionario que insiste "en llevar ritualmente durante el ejercicio de sus funciones una toca con el objeto de manifestar ostensiblemente su pertenencia religiosa y de expresar su devoción a un culto, comportamiento que denota una transgresión deliberada del principio de laicidad del Estado al que se le confiere valor constitucional en virtud del artículo 2 de la Constitución del 4 de octubre de 1958, constituye un incumplimiento del honor profesional que implica necesariamente la deontología del servicio público"37. La jurisprudencia dicta constantemente que las medidas disciplinarias a adoptar en caso de incumplimiento de la obligación de neutralidad de los agentes públicos han de determinarse teniendo en cuenta la naturaleza y el grado del carácter ostentoso del signo, así como el resto de las circunstancias en las que se hubiera constatado el incumplimiento ${ }^{38}$.

Sin lugar a dudas, la obligación de neutralidad de los agentes se puede valorar de manera distinta dependiendo del lugar en el que se manifieste. En otros términos, seguramente existen ámbitos más sensibles que otros, como puede ser, por ejemplo, la enseñanza en las escuelas públicas ${ }^{39}$. A este respecto, Jules Ferry, en su circular de marzo de 1885, dirigida a los profesores de primaria, comentaba: "No se podrá decir nunca que tratáis con demasiados escrúpulos algo tan delicado y sagrado como es la conciencia de un niño".

33 M. Picard, "La laïcité dans la fonction publique”, Cahiers de la fonction publique, 2004, p. 4; J. Berthoud, “La neutralité religieuse du fonctionnaire”, JCP A 2005, n. 1142.

34 CE dictamen del 3 de mayo de 2000, AJDA 2000, p. 63, cron. M. Guyomar y P. Colin.

35 CE del 15 de octubre de 2003 , Odent.

36 CE del 12 de febrero de 1997, Mlle Henny.

37 TA de Lyon del 8 de julio de 2003, n. 0201383 , Nadjet Ben A., JCP A 2003, 2026, obs. A. Taillefait; CAA Lyon del 27 de noviembre de 2003, n. ${ }^{\circ} 03$ LY01392, Nadjet Ben A., AJDA 2004, p. 154, nota de F. Melleray.

38 En este sentido véase por ej. TA de París del 22 de febrero de 2007, n. 0415268-5-2, B; AJFP de julio de 2007, p. 208.

39 M. Grawitz, “La liberté de l'enseignant dans l'enseignement secondaire français", Mélanges $R$. p. 35. Véase CE del 10 de mayo de 1912, Abbé Bouteyre, Rec. 553, concl. Helbronner. 
Evidentemente, el caso del abad Bouteyre, donde se consideró justificada la exclusión de un eclesiástico de la lista de los candidatos autorizados a pasar las pruebas de las oposiciones a cátedra de filosofía de la enseñanza escolar, ya pertenece al pasado. Tal y como indica el dictamen del Consejo de Estado del 21 de septiembre de 1972: "Aunque las disposiciones constitucionales que establecieron la laicidad del estado y de la enseñanza imponen la neutralidad de todos los servicios públicos y, en particular, la neutralidad de la enseñanza en lo que respecta a todas las religiones, no se oponen por sí mismas a que las funciones de dichos servicios se confieran a miembros del clero". No obstante, el "principio de neutralidad escolar" 40 permanece. Prevalece incluso más allá de las cuestiones religiosas. De este modo, los propósitos revisionistas suponen un incumplimiento de la obligación de neutralidad impuesta a todo funcionario, "particularmente grave si se trata de un profesor de colegio" ${ }^{41}$ de historia, geografía y educación cívica. En el pasado, un profesor que se había aprovechado de sus funciones "para propagar una enseñanza tendenciosa claramente germanófila y bajo el ángulo de la colaboración" pudo ser legalmente objeto de una medida de depuración a la Liberación ${ }^{42}$.

Por el contrario, la neutralidad no es requisito para la enseñanza superior pública en la medida en que la enseñanza impartida y el carácter de las personas a las que se dirige "dispensan en principio al Estado de hacerse responsable de las doctrinas que se enseñan. Los oyentes y los estudiantes tienen en este caso edad suficiente para juzgar por sí mismos"43. Esta tradición confirma hoy en día el principio constitucional de independencia de los profesores de universidad, principio fundamental reconocido por las leyes de la República ${ }^{44}$.

\section{En materia política, la neutralidad se divide en dos grandes obligaciones.}

Por una parte, la obligación de lealtad con respecto al poder político explica varias soluciones jurisprudenciales ${ }^{45}$. Hay que recordar que, si bien la función pública de carrera protege a los agentes de los avatares políticos, los somete por otro lado a una “obligación de lealtad ante las instituciones de la República" ${ }^{46}$. Por tanto, los funcionarios deben seguir las instrucciones que se les dictan sin realizar valoraciones personales al respecto, y no pueden tomar partido por los candidatos ni por las listas de candidatos durante las campañas electorales ${ }^{47}$. No obstante, existen determinados empleos que más que lealtad exigen una verdadera adhesión y confianza. Por este

40 CE del 4 mayo de 1948, Connet.

41 CE del 22 de noviembre de 2004, Ministre de la jeunesse et de l'éducation C. M. Adam, JCP A 2005, n. ${ }^{\circ} 1040$, nota de D. Jean-Pierre ; JCP G 2005, I, 121, obs. E. Aubin.

42 CE del 5 de marzo de 1947, Dame Laroche, Rec. tab. 603.

43 Heilbronner, concl. sobre el CE del 10 de mayo de 1912, Abbé Bouteyre, Rec. 553.

44 CC 83-165 DC, 20 de enero de 1984, Libertés universitaires, Rec. 30.

45 A modo de ejemplo, el funcionario que critica "a la innoble bandera tricolor" comete una falta disciplinaria: CE del 25 de enero de 1935, Defrance, p. 105.

46 CE del 12 de diciembre de 1997, Serge L., Rev. adm. 1999, p. 391, nota de F. Lafaille. Véase también el artículo 7 del Código deontológico de la policía nacional. Igualmente, J.-F. Flauss, “Le devoir de loyauté politique des fonctionnaires", AJDA 1994, p. 519.

47 CE del 29 de julio de 1927, Elections au conseil général de Sainte-Croix, Rec. 855. 
motivo, tras un cambio de mayoría municipal, se puede entender perfectamente que un alcalde ponga fin al cargo de su secretario general alegando como único motivo el interés del servicio para el que se requiere "una complicidad total entre el alcalde y su primer colaborador" 48 .

Por otra parte, se impone un requisito de reserva política a los agentes públicos. Naturalmente los agentes públicos, en el marco de su actividad profesional, no deberían desarrollar actividades de propaganda política ni utilizar sus funciones para este tipo de actividades ${ }^{49}$. Así, un candidato que crea una asociación formada esencialmente por empleados municipales con el objeto de organizar loterías para apoyar su campaña electoral estaría mostrando una falta de objetividad ${ }^{50}$. Por el contrario, que los funcionarios municipales acudan a la puerta de los colegios electorales con una copia del censo electoral no merma en modo alguno la libertad de voto, ya que no se considera que el hecho de poner el censo a disposición de los agentes municipales tenga como objetivo ejercer presión sobre los votantes ${ }^{51}$. Esta última decisión ha recibido amplias críticas de la doctrina: “No es lógico que el Consejo constitucional, en este caso, no haya calificado tal comportamiento de anormal y que no lo haya condenado firmemente, al menos desde el punto de vista moral. Es de cajón que la copia del censo electoral permitía a los agentes municipales saber qué ciudadanos se abstenían, para así poder ponerse en contacto con ellos e incitarlos a ir a votar" ${ }^{2}$.

Cabe recordar que esta obligación de lealtad solamente se puede exigir durante el desempeño de sus funciones: “Los agentes públicos, fuera del desempeño de sus funciones, cuentan con total libertad para manifestar su opinión, aunque sea hostil a los gobiernos al mando, siempre que no menoscabe la lealtad que el propio país tenga derecho a esperar de sus ciudadanos"53.

\section{El principio de objetividad de la acción administrativa}

Como es de todos sabido, el principio de imparcialidad de la acción administrativa, erigido en principio general de derecho a partir de 1949 de forma implíci$\operatorname{ta}^{54} \mathrm{y}$, posteriormente, de forma explícita55, y “las reglas deontológicas que de él

48 TA de Dijon del 16 de junio de 1998, Sylbie G. c. Commune de Montbard, AJFP nov-dic. 1998, p. 51.

49 CE del 8 de diciembre de 1948, Pasteau, Rec. 464.

50 CE del 25 de octubre de 1993, Salvan, req. 139441.

51 CC 97-2155, 14 de octubre de 1997, Eglise de scientologie de Paris, AJDA 1992, p. 460, obs. C. Devès.

52 D. Jean-Pierre, L'éthique du fonctionnaire civil, LGDJ, 1999, p. 188.

53 G. Burdeau, Traité de Science politique. La démocratie et les contraintes d'un nouvel âge, t. VIII, LGDJ, 1974, p. 230. En este sentido véase también J. Rivero, nota del CE del 8 de diciembre de 1948, Pasteau, S. 1949, III, 41: “la neutralité est la loi commune de tous les agents publics dans l'exécution de leur service".

54 CE del 4 de marzo de 1949, Trèbes, Sirey 1950, III, p. 21. Véase también el CE del 29 de abril de 1949, Bourdeaux, Rec. 488.

5 CE del 27 de octubre de 1999, Fédération française de football, JCP 2000, n. ${ }^{\circ}$ 10376, nota de R. 
se derivan" son de obligado cumplimiento para todo "organismo administrativo" 56 . No obstante, el requisito de objetividad en la acción administrativa no deriva tanto directamente de la imparcialidad como del principio de igualdad, situado en el propio centro neurálgico del derecho administrativo francés. De forma paralela, el principio de objetividad fundamenta el exceso de poder: en este sentido, los comportamientos y los actos que carezcan de objetividad se pueden tachar de ilegales.

\subsection{La objetividad condicionada por la igualdad}

A menudo la neutralidad de los servicios públicos no se considera una regla autónoma de dichos servicios, sino que tradicionalmente se ha venido vinculando al principio de igualdad. Consiste en no hacer diferencia alguna entre los usuarios de los servicios públicos en función de sus opiniones, se trata de "una neutralidad por la no discriminación por razón de opiniones" 57 . Por este motivo, los municipios solamente pueden hacerse cargo legalmente de gastos de interés general y no pueden participar en el mantenimiento de las vías privadas, por ejemplo ${ }^{58}$.

La igualdad se declina sucesivamente en múltiples subprincipios.

En un primer momento, se manifiesta a través del principio de neutralidad que debe guiar la acción administrativa. Según la definición ofrecida por el profesor René Chapus, el principio de neutralidad "prohíbe que el servicio público se asegure de forma diferente en función de las convicciones políticas o religiosas de su personal o de los usuarios del servicio" ${ }^{59}$. Según este principio, el servicio público no podrá privilegiar a un determinado usuario o grupo de usuarios ${ }^{60}$ y deberá abstenerse de manifestar sus propias convicciones ${ }^{61}$. Se trata de un principio que se observa con rigor. Por ejemplo, la administración ni siquiera puede alegar consideraciones de humanidad para oponerse a prestar ayuda mediante la fuerza pública para la ejecución de una sentencia de expulsión ${ }^{62}$. En la misma línea, la decisión de un alcalde de cerrar los servicios públicos municipales durante un día para apoyar una huelga constituye una violación del principio de neutralidad del servicio público ${ }^{63}$.

56 CE del 7 de julio de 1965, Fédération nationale des transports routiers, Rec. 413 ; CE Secc. del 5 de mayo de1995, Burruchaga, Rec. 197.

57 J. Rivero, Libertés publiques, PUF, 1977, t. 2, p. 130.

58 CE del 17 de octubre de 1990, Mme Braesch et autres, Rec. 625.

59 R. Chapus, Droit administratif général, t. 1, Montchrestien, 2001, p. 609.

60 CE del 17 de febrero de 1992, Eglise de Scientologie de Paris, Rec. 61; AJDA 1992, p. 460, nota de C. Devès.

61 CE del 8 de noviembre de 1985, Ministre de l'Education nationale c. Rudent, Rec. 316; CE del 6 de noviembre de 1991, Ministre de l'Education nationale c. Confédération des groupes autonomes de l'enseignement public, Rec. 377.

62 CE del 19 de noviembre de 1948, Epoux Girard, Rec. tab. 639.

63 CE del 23 de junio de 2004, Communauté urbaine de Dunkerque, req. n. 250294. 
El mismo año que el que se dictó el fallo sobre el caso Barel, se juzgó que la pertenencia a un partido comunista no era motivo para cesar en sus funciones a un inspector de la academia ${ }^{64}$. Igualmente, se consideró que la administración no tenía derecho a dejar en un expediente de candidatura transmitido al jurado una mención sobre las opiniones políticas y la afiliación sindical del candidato ${ }^{65}$. En su relación con los agentes, la administración no debe tener en cuenta la opinión de aquéllos para concederles o negarles un ascenso ${ }^{66}$. Es ilegal negarle un ascenso a un ingeniero de caminos por el único motivo de sus opiniones políticas ${ }^{67}$. Citaremos un último ejemplo: durante el referéndum del 29 de mayo de 2005 sobre el tratado que establecía una Constitución para Europa, el gobierno había distribuido en las escuelas un folleto explicativo editado por la Comisión europea favorable al "sí”. El Partido comunista francés, partidario del “no", apeló entonces al respeto de la neutralidad del servicio público. El juez el Consejo de Estado encargado del procedimiento abreviado juzgó que el documento objeto del litigio había sido editado y financiado por la Comisión que presentaba el tratado con fines informativos y que, por consiguiente, "la decisión de autorizar la difusión de un documento de estas características entre los alumnos de institutos no constituye un incumplimiento grave ni manifiestamente ilegal de los principios de la libertad de expresión del sufragio y de neutralidad del servicio público"68.

No resulta anodino señalar que las instalaciones de la República son lugares neutros, tal y como queda de manifiesto con la prohibición de fijar signos religiosos en los edificios públicos ${ }^{69} \mathrm{o}$ una bandera independentista en el frontón de un ayuntamiento martiniqués ${ }^{70}$, o de engalanar el interior de los colegios electorales hasta la urna con los colores de un determinado partido político ${ }^{71}$.

La neutralidad, consecuencia de la igualdad, adopta la forma de laicidad, lo que "implica que el Estado no ejerza ningún poder religioso y que las iglesias no ejerzan ningún poder civil"72. Pensamos en la ley del 15 de marzo de 2004, que, apli-

64 CE Secc. del 1 de octubre de 1954, Guille, Rec. 496.

65 CE del 28 de septiembre de 1988, Merlenghi, Rec. 316.

66 CE del 23 de abril de 1963, Durrieux, Rec. 242.

67 CE del 21 de diciembre de 1960, Vicat-Blanc, Rec. tab. 1022.

68 CE ord. del 13 de mayo de 2005, Marie-George Buffet et a., req. n. ${ }^{\circ} 280353$.

69 CAA Nantes del 4 de febrero de 1999, n. 98 NT00207, Association civique Joué Langueurs, Rec. 1999, tabla 498: retirada obligatoria de un crucifijo en un ayuntamiento de Vendée. Véase también CAA de Nantes del 11 marzo de 1999, Une Vendée pour tous les vendéens, Rec. 776: si, por el contrario, el juez admite que se fije en el frontón de los colegios públicos el logotipo del departamento de la Vendée, con la representación de dos corazones entrelazados con una corona que lleva una cruz, es porque "aun en el caso de que se pudiese disociar cada uno de los elementos y de que éstos representasen un motivo religioso por separado, el logotipo, que no se ha realizado con una finalidad de manifestación religiosa ni tiene por objeto promover una determinada religión, cumple la única función de identificar la acción del departamento mediante referencias históricas y un grafismo estilizado".

70 CE del 27 de julio de 2005, Commune de Sainte-Anne, Pliegos de la función pública, noviembre de 2005, p. 31, nota de M. Guyomar ; BJCL n. ${ }^{\circ} 10 / 05$, p. 676, concl. F. Donnat.

71 CE del 15 de noviembre de 2004, Elections Ass. Polynésie française, Rec. 426.

72 J.-M. Delarue, concl. sobre el CE del 7 de mayo de 1997, Ministre de la justice c. Dodu, req. n. ${ }^{\circ}$ 292 152601. El Consejo de Estado ha confirmado recientemente el principio de neutralidad en los cultos y el 
cando el principio de laicidad, trata la cuestión de llevar puestos signos o vestimentas que manifiesten una determinada creencia religiosa en escuelas, colegios e institutos públicos ${ }^{73}$. Lo que prohíbe la laicidad no son las religiones ni las convicciones, sino un proselitismo en los lugares donde se desempeña un servicio público y en el momento de su desempeño. En este sentido, el hecho de que los miembros de una congregación religiosa participen en un servicio penitenciario, bajo la estricta condición de la ausencia de proselitismo, "no transgrede el principio de laicidad ni el de neutralidad del servicio público"74. Igualmente, se les reconoce a los alumnos el derecho de beneficiarse de una autorización para ausentarse cuando sea necesario para el ejercicio de un culto o la celebración de una fiesta religiosa, siempre que sea compatible con la organización de los estudios y el respeto del orden público en el establecimiento ${ }^{75}$.

\subsection{La objetividad, condición de la legalidad}

El principio de objetividad puede manifestarse como condición de legalidad de los actos administrativos. De hecho, existen disposiciones legislativas y reglamentarias que vinculan expresamente la violación del principio de imparcialidad y de ilegalidad del acto. Por ejemplo, los miembros de las comisiones administrativas no pueden "participar en las deliberaciones cuando tengan un interés personal en el asunto de debate", so pena de tener que declarar nula la resolución adoptada tras dichas deliberaciones cuando no se pueda mostrar que la participación del miembro o de los miembros interesados no haya influido en la decisión"76. Lo mismo ocurre con los miembros de los órganos deliberativos de colectivos territoriales y sus agrupaciones ${ }^{77}$. Estas limitaciones se pueden aplicar igualmente por intereses pasados. Así, los miembros de la Autoridad de los mercados financieros no pueden deliberar en un asunto en el que tengan algún tipo de interés, por estar implicada una persona jurídica en la que hubiesen ocupado algún cargo o para la que hubiesen ejercido algún mandato durante los dos años precedentes ${ }^{78}$. De igual modo, los miembros de la $\mathrm{CNIL}^{79}$, de la HALDE ${ }^{80}$ y de $\mathrm{HADOPI}^{81}$, en materia de sanciones, no pueden participar en deliberaciones ni proceder a realizar verificaciones relativas a un organismo en el que tengan o hubiesen tenido en los tres años precedentes algún tipo de interés, di-

principio de igualdad que excluyen cualquier liberalidad y, por consiguiente, cualquier ayuda a un determinado culto: CE As. del 19 de julio de 2011, Communauté urbaine du Mans, req n. ${ }^{\circ} 309161$; Commune de Montpellier, req. n. ${ }^{\circ} 313518$.

$73 \mathrm{JO}$ del 17 de marzo de 2004, p. 1510.

74 CE del 27 de julio de 2001, Syndicat national pénitentiaire, Rec. 393.

75 CE As. del 14 de abril de 1995, Koen y Consistoire central des israélites de France, Rec. 168.

76 Artículo 13 del decreto n. ${ }^{\circ} 2006-672$ del 8 de junio de 2006.

77 Artículo L. 2131-11 del código general de las administraciones territoriales para los consejos municipales.

78 Artículo L. 621-4 del código monetario y financiero.

79 Artículo 14-Il de la ley del 6 de enero de 1978.

80 Artículo 3 de la ley del 30 de diciembre de 2004.

81 Artículo L. 3331-18 del código de la propiedad intelectual. 
recto o indirecto, o en donde ocupen o hayan ocupado un cargo o ejerzan o hayan ejercido algún tipo de mandato.

El derecho que regula las contrataciones administrativas ofrece muy buenos ejemplos de cómo se toma en consideración la objetividad en el derecho administrativo.

En cuanto a las oposiciones de la administración ${ }^{82}$, los jueces se apoyan en el principio de orden general de sinceridad y de imparcialidad que preside el buen desarrollo de las oposiciones ${ }^{83}$. La composición del jurado ha de determinarse de tal manera que no pueda cuestionarse su imparcialidad, es decir, los candidatos no podrán carecer de las "garantías de imparcialidad que deben asistir a todo candidato" Los jueces comprueban que los miembros del jurado no favorezcan ni perjudiquen a ningún candidato.

La actitud parcial de un jurado supone la nulidad de las actividades de la oposición ${ }^{85}$, si bien suele ser complicado probar la existencia de parcialidad. La mera presencia en el jurado de miembros que conozcan a determinados candidatos no sería suficiente para tildar de ilegal una decisión adoptada ${ }^{86}$.

En general, se pueden dar tres situaciones que demuestran la parcialidad del jurado. En primer lugar, puede ocurrir que los miembros del jurado hayan adoptado una actitud explícitamente hostil con respecto a determinados candidatos o categorías de candidatos. Lo mismo sucede si un alcalde indica en una ordenanza que sería preferible, en aras del interés del servicio, contratar a un secretario de alcalde de sexo masculino para ocupar el puesto de teniente de alcalde ${ }^{87}$. En segundo lugar, se puede poner en duda la reputación de los miembros del jurado en el transcurso del examen de los proyectos de los candidatos ${ }^{88}$ cuando existan, por ejemplo, dos jefes de servicio entre los cinco miembros del jurado, o cuando haya en dicho jurado una persona con vínculos muy estrechos con un candidato: su padre ${ }^{89}$, su suegro ${ }^{90}$, su

82 B. Lasserre y J.-M. Delarue, "Le juge et les concours de recrutement de fonctionnaires", $A J D A$ 1983 , p. 533

83 CE Secc. del 30 de enero de 1931, Sieur Vaulot, Rec. 113.

84 CE del 20 de octubre de 1999, Bailleul, DA 2000, n. ${ }^{\circ} 13$, obs. C. Moniolle. Véase anteriormente CE Secc. del 30 de enero de 1931, Sieur Vaulot, Rec. 113: "principe d'ordre général de sincérité et d'impartialité" que debe presidir el buen desarrollo de las oposiciones.

85 CE del 27 de octubre de 1965, Ministère de l'Education nationale, Rec. 557.

86 En este sentido, B. Lasserre y J.-M. Delarue, AJDA 1983, cron. sobre el CE del 20 de septiembre de 1981, Blaszsek, Rec. 990.

87 CE Secc. del 4 de noviembre de 1956, Commune de Clohars-Carnoët, Rec. 591.

88 CE del 18 de marzo de 1993, Spina, req. n. 33379 . Véase también el CE del 20 de septiembre de 1991, Blazsek, AJDA 1992, p. 163, obs. O. Schrameck: la presidencia del jurado que deliberaba sobre los proyectos de los candidatos sobre las funciones de encargados de investigación del CNRS estaba ocupada por el director del laboratorio en el que habían trabajado dos de los cuatro candidatos admisibles y únicos admitidos.

89 CE del 10 de febrero de 1922, Sieurs Aldeguer et Branlière, Rec. 127.

90 CE del 5 de octubre de 1955, X., D. 1956, somm. 74: se debe anular, por haber derivado de un procedimiento irregular, el nombramiento de un profesor de diseño en la Escuela politécnica porque el 
exmarido ${ }^{91} \ldots$ Y, por último, un miembro del jurado puede actuar bajo la autoridad de uno de los candidatos ${ }^{92}$.

En otros casos, el Consejo de Estado se niega a ver una actitud parcial. Así, las diferencias que haya podido tener un candidato con uno de los miembros del jurado no bastan para viciar el procedimiento93, ni el hecho de que un miembro del jurado de la oposición conozca a un candidato ${ }^{94}$. Igualmente, el asesoramiento que un miembro del jurado pudiese haber dado con carácter previo a la apertura de la oposición no constituye una violación del principio de imparcialidad 95 . Por el contrario, según la jurisprudencia tradicional, quedan terminantemente prohibidos los contactos personales de los miembros del jurado con los candidatos una vez abierta la fecha de la oposición ${ }^{96}$. Y por último, en caso de que uno de los miembros del jurado abandone la sala durante la prueba oral de un determinado candidato bajo el pretexto de aplicar con rigor el principio de imparcialidad, creando así una desigualdad de trato entre los candidatos, estaría violando el principio de igualdad ${ }^{97}$.

El principio de objetividad debe estar presente también en los procesos de contratación exterior, es decir, en los modelos de contratación que, para determinados grados y en una proporción determinada, cubren algunos puestos mediante la incorporación de personas cuya carrera se hubiese desarrollado hasta entonces fuera de la institución en cuestión. Dichos modelos se pueden ver, de forma positiva, como un medio de promoción interna y de apertura hacia la sociedad civil, o, de forma negativa, como una forma de recompensar, proteger o incluso consolar... ${ }^{98}$. En este ámbito, la valoración de las capacidades de las personas susceptibles de ser designadas o nombradas corresponde a un juez administrativo, que deberá velar por que no se produzcan errores manifiestos de valoración. En este sentido, se incurriría en un error manifiesto al nombrar para la inspección general de las bibliotecas a una persona que hubiera comenzado su carrera en la marina mercante y que no poseyera experiencia alguna en el ámbito bibliotecario y de la información científico-técnica ${ }^{99}$. De igual modo, un juez anuló un decreto de contratación externa en Quai d'Orsay porque pretendía burlar lo estipulado en el estatuto de los agentes diplomáticos para contratar a un secretario de asuntos exteriores que, objetivamente, no podía ser nombrado legalmente embajador ni jefe de misión diplomática ${ }^{100}$.

consejo de perfeccionamiento, que tenía que presentar dos candidatos, estuvo presidido por el cuñado de la persona que se nombró.

91 CE del 10 de febrero de 1995, Perrin Rec. 851.

92 CE del 4 de febrero de 2004, Attar, Rec. tab. 715.

93 CE del 8 de marzo de 1996, Bans, req. n. ${ }^{\circ} 102010$.

94 CE Secc. del 18 de julio de 2008 , Baysse, req. n. 291997.

95 CE del 20 de marzo de 1985, M. Didier, req. n. 37259.

96 CE Secc. del 21 de enero de 1966, Baumel, Prioton et Vidal, Rec. 50.

97 CE del 9 de julio de 2007, Thoubert, Rec. tab. 880. Cabe destacar que esta solución es válida para las oposiciones, pero no se aplica a los exámenes: CE Secc. del 18 de julio de 2008, Baysse, Rec. 302.

98 O. Schrameck, "Fonction publique de l'Etat. Influences politiques et garanties juridiques", $A J D A$ 1994 p. 429; Y-M. Doublet, "Nominations au tour extérieur et pantouflage dans la haute fonction publique. A propos de la loi n. ${ }^{\circ} 94-630$ du 28 juin 1994", RFDA 1995, p. 716.

99 CE As. del 16 de diciembre de 1988, Bleton, Rec. 451.

100 CE As. del 31 de mayo de 2006, Syndicat CFDT du ministère des affaires étrangères, req. n. 269635. 
Llegamos, por tanto, a la conclusión de que el principio de objetividad no deriva única y exclusivamente de una acumulación de casos jurisprudenciales, sino que se construye poco a poco.

\section{LA CONSTRUCCIÓN DEL PRINCIPIO DE OBJETIVIDAD EN EL DERECHO ADMINISTRATIVO FRANCÉS}

El tratamiento de la objetividad en el derecho administrativo francés es de orden a la vez preventivo, dado que se basa en la elaboración de reglas deontológicas, y represivo, dado que se apoya en los principios liberales de anulación de los actos ilegales y de compromiso de la responsabilidad de los agentes públicos.

\section{La prevención de la falta de objetividad por la deontología administrativa}

Según la definición que ofrece M. Vigouroux, la deontología “es un conjunto de principios de acción enfocados hacia las prácticas profesionales que hacen posible el servicio público por la confianza de los usuarios, el respeto de las misiones definidas por la ley y la aceptación de las obligaciones de la acción colectiva”101. Se trata, en cierta manera, de la "moral profesional" que se impone a los agentes públicos y que hay que combinar con la exigencia creciente de una buena administración ${ }^{102}$.

\subsection{La prevención de la parcialidad}

La idea es ya antigua: tradicionalmente evocamos el requisito de imparcialidad administrativa desde la ordenanza de Philippe Le Bel del "lunes después de la MiCarême" del 23 de marzo de $1302^{103}$, verdadero código de conducta que define los deberes y las prerrogativas de los funcionarios, y premisa de una deontología de los funcionarios. En este documento encontramos una manifestación del principio de objetividad: los agentes públicos “jurarán que harán justicia a los grandes y a los pequeños y a todas las personas, independientemente de su condición”104.

Desde entonces el principio de objetividad no ha parado de ganar terreno, contribuyendo a la construcción de una ética profesional de la función pública ${ }^{105}$. Vista

101 Ch. Vigouroux, Déontologie des fonctions publiques, Dalloz, 2006.

102 R. Bousta, Essai sur la notion de bonne administration en droit public, L'Harmattan, 2010 ; B. Delaunay, "La faute de l'administration", LGDJ, 2007, p. 78 s.

103 Recueil général des anciennes lois françaises, t. II, Isambert, p. 759.

104 Artículo 40. Bajo un ángulo similar, véase la ordenanza de Louis IX de 1254 sobre la reforma de la administración y de la policía del reino: "harán justicia a todos, sin excepción alguna, tanto a los pobres como a los ricos, a las personas cercanas y a las ajenas".

105 F. Chambon y O. Gaspon, La déontologie administrative, LGDJ, col. Systèmes, 1997; D. Jean-Pie296 re, La déontologie administrative, LGDJ, col. Que sais-je?, 1999. 
como una alternativa a las sanciones disciplinarias, civiles o penales impuestas a los agentes que hubieran faltado a su deber de objetividad en sus acciones, la elaboración de una deontología administrativa parece así mismo la solución más eficaz. Se puede apoyar en los principios asentados en el extranjero o incluso en el marco de la Unión Europea, habiendo desvelado los jueces de la Unión, con respecto a los funcionarios europeos, "una obligación general de independencia y de probidad para con la institución" y prohibiendo "de manera general, todo comportamiento ligado o no al incumplimiento de una reglamentación particular que, en vista de los elementos disponibles, muestra que el funcionario en cuestión pretendió favorecer un interés particular en detrimento del interés general comunitario" ${ }^{106}$.

Contrariamente a lo que prevalece en el seno de las jurisdicciones administrativas, las reglas de incompatibilidad y de recusación son escasas, no habiéndose entablado procedimiento alguno de recusación en lo administrativo no contencioso ${ }^{107}$, salvo que hubiese sido previsto por un texto específico ${ }^{108}$.

A día de hoy existen pocos instrumentos deontológicos. No obstante, podemos citar una circular del 28 de marzo de 2001 relativa a las relaciones con el mundo profesional instituyendo un "código de buena conducta de las intervenciones en medios escolares" en el que el ministro de Educación nacional recuerda que "el principio de neutralidad del servicio público de la educación nacional está en línea con la neutralidad comercial” ${ }^{109}$. Por tanto, la inserción en una publicación administrativa de folletos publicitarios solamente es posible si se puede "ver como respuesta a un interés público o como el complemento o la prolongación de la actividad del servicio público, que aquí también es la información de los funcionarios y de los administrados"110. Podemos igualmente citar la carta de la laicidad en los servicios públicos publicada por el Primer ministro ${ }^{111}$, anunciada en los lugares públicos, que recuerda que "el hecho de que un agente público manifieste sus convicciones religiosas en el ejercicio de sus funciones constituye un incumplimiento de sus obligaciones". La carta añade que "Ios responsables de los servicios públicos se encargarán de hacer respetar la aplicación del principio de laicidad en el marco de sus servicios" 12 .

106 TPICE del 9 de julio de 2002, Zavvos c. Commission, aff. T-21/02.

107 CE Secc. del 27 de abril de 1988, Sophie, Rec. 160, concl. S. Hubac, AJDA, 1988, p. 446, cron. Sr. Azibert y Sr. de Boisdeffre.

108 CE del 9 de marzo de 1938, Huguet, Rec. 251; CE del 6 de mayo de 1955, Esch Chadely, Rec. 238 ; CE del 14 de noviembre de 2008, Guerra, Rec. 419.

109 Circular n. $2001-053$, BOEN n. ${ }^{\circ} 14$ del 5 de abril de 2001.

110 CE Secc. del 6 de noviembre de 2002, Milinieri, JCP A 2002, n. ${ }^{\circ}$ 1352, nota de A. Taillefait, retomando un dictamen del Consejo de Estado del 19 de noviembre de 1987.

111 Circular n. ${ }^{\circ}$ 5209/SG del 13 de abril de 2007.

112 Anteriormente, la circular del 2 de febrero de 2005 relativa a la laicidad en los establecimientos sanitarios había precisado los derechos y deberes del personal sanitario y de los pacientes. Para una aplicación en el contencioso: CAA de Lyon del 10 de junio de 2008, n. ${ }^{\circ}$ 05LY01218, Radouane I. c. CH Bourg-enBresse, JCP A 2009, 2083, cron. M.-L. Moquet-Anger. 
La deontología de los agentes tiene repercusiones en la deontología de la administración. El profesor Bienvenu ha mostrado en este sentido que los destinatarios de las normas deontológicas no son únicamente los agentes públicos, sino que, por el contrario, éstas amplían sus efectos a la propia administración. Cita a título de ejemplo las conclusiones del comisario del gobierno Piveteau sobre la orden Lambda: "si los legisladores han querido que los agentes sean irreprochables es para que la administración sea irreprochable". Podemos concluir que "la regla deontológica ya ha cambiado de destinatario: ya no son los funcionarios, sino el servicio" "113. La norma penal represiva que prohíbe a los funcionarios albergar intereses de forma ilegal resulta en una regla deontológica para la administración en el ejercicio de su poder de nombramiento. Bienvenu concluye que confrontar la deontología de los agentes con la de la administración conduce a "un equilibrio tan inestable como el de la relación entre la falta personal y la falta de servicio. $Y$, haciendo uso de un plagio, añade, diría que la deontología se desvincula quizás de la falta, pero nunca el servicio de la deontología"114.

\subsection{Prevención de los conflictos de intereses}

En la época contemporánea, el debate se centra en la prevención de los conflictos de intereses en la vida administrativa. Recordemos que "un conflicto de intereses implica un conflicto entre la misión pública y los intereses privados de un agente público, en el que el agente público posee a título privado intereses que podrían influir indebidamente en la forma en la que cumple con sus obligaciones y responsabilidades"115. Más exactamente, un conflicto de intereses "nace de una situación en la que un agente público tiene un interés personal susceptible de influir o que pueda parecer que influye en el ejercicio imparcial y objetivo de sus funciones oficiales. El interés personal del agente público engloba cualquier ventaja para sí mismo o a favor de su familia, parientes, amigos o personas cercanas, o de personas u organizaciones con las que tenga o haya tenido relaciones de negocios o políticas. Engloba, así mismo, toda obligación financiera o civil a la que esté sujeto el agente público"116.

Por supuesto, Francia dispone de una legislación sobre los conflictos de intereses, además de diversas instituciones de control (inspecciones y jurisdicción), pero es ya antigua, esencialmente represiva y se aplica poco. El respeto de la objetividad implica sobre todo la independencia de los funcionarios con respecto a las fuerzas económicas privadas y, por tanto, la gestión de las salidas de funcionarios hacia el sector

113 J.-J. Bienvenu, "Déontologie et standards administratifs" en Les règles et principes non écrits en droit public, París, ed. Panthéon-Assas, 2000, p. 248.

$114 \mathrm{Ibid}$. Reconocemos la fórmula de L. Blum en sus conclusiones sobre el CE del 26 de julio de 1918 , Lemmonier, Rec. 761: "la falta se desvincula quizás del servicio, pero el servicio nunca se desvincula de la falta “.

115 OCDE, Lignes directrices, 2005.

116 Consejo de Europa, Recomendación n. ${ }^{\circ} \mathrm{R}$ (2000) 10 del Comité de ministros sobre los códigos 298 de conducta para los agentes públicos del 11 de mayo de 2000. 
privado, es decir, la limitación de las huidas al sector privado. El Consejo de Estado anuló la asignación de un alto funcionario de finanzas para ocupar el puesto de subgobernador de un banco público ${ }^{117}$ basándose en que incumplía el artículo 432-13 del Código penal ${ }^{118}$ y negó a un funcionario la posibilidad de ocupar durante el ejercicio de sus funciones un puesto de trabajo en una empresa que era antes de su propiedad, aun bajo supervisión. Así se sanciona la versión negativa del pase al sector privado, el hecho de abandonar la administración para formar parte de una empresa privada. El trabajo de la comisión de deontología (frase inacabada en el original).

Además, también hay textos que tienen en cuenta los intereses de las personas cercanas a los actores públicos. El artículo 35 de la ley n. ${ }^{\circ}$ 2010-476 del 12 de mayo de 2010 prevé que la Autoridad reguladora de los juegos en línea (ARJEL) determine en su reglamento interior las modalidades de prevención de conflictos de intereses. Como resultado, los miembros de la ARJEL no pueden deliberar en un asunto en el que hayan tenido algún tipo de interés o hubiesen sido parte interesada en el transcurso de los dos años precedentes a la deliberación. La misma prohibición se impone cuando se encuentre en la misma situación un miembro de su entorno directo o, en su caso, una persona jurídica para la que haya desempeñado algún cargo u ostentado algún mandato durante el periodo referido de dos años.

Recientemente entregado al Presidente de la República, en el informe de la Comisión de reflexión para la prevención de conflictos de intereses en la vida pública Por una nueva deontología de la vida pública ${ }^{119}$ se formula una serie de propuestas que van a dar lugar a una ley actualmente en preparación. En particular, se plantea la creación de una Autoridad de deontología de la vida pública, que retomaría las misiones de la actual Comisión para la transparencia financiera de la vida política y la Comisión de deontología, a las que se añadirían las misiones de prevención de conflictos de intereses en la esfera públi$\mathrm{ca}^{120}$. Además, la elaboración de códigos de conducta o de cartas de deontología en cada autoridad administrativa, enunciando el conjunto de deberes de los actores públicos, se antoja, por consiguiente, indispensable. Dichos códigos deberán ir acompañados de guías prácticas en donde, a partir de casos concretos, se expongan las situaciones problemáticas en las que se pueden encontrar los interesados y que aporten los elementos de respuesta en cuanto al comportamiento a seguir o a los errores que hay que evitar, de forma similar a lo que hace un número cada vez mayor de empresas privadas ${ }^{121}$.

117 CE As. del 6 de diciembre de 1996, Société Lambda, Rec. 466, concl. D. Piveteau.

118 "Se castigará con dos años de privación de libertad y con una multa pecuniaria de 30.000 euros el hecho de que una persona que, en tanto que funcionaria o agente de una administración pública y en el marco de las funciones que haya desempeñado efectivamente, hubiese estado a cargo de garantizar la supervisión o el control de una empresa privada, o de celebrar cualquier tipo de contrato con una empresa privada, o de formular dictámenes sobre dichos contratos, o de proponer directamente a la autoridad competente decisiones relativas a las operaciones realizadas por una empresa privada, o de formular dictámenes sobre dichas decisiones, tome o reciba una participación por trabajo, asesoramiento o capitales en alguna de las empresas mencionadas antes de finalizar el plazo de tres años tras el cese de dichas funciones".

119 J.-M. Sauvé, D. Migaud, J.-C. Magendie, Documentación francesa, enero de 2011

120 Ibid, p. 91.

121 Ibid, p. 95. 
Además, habrá que desarrollar respuestas a las demandas e intervenciones exteriores que puedan conducir a que los funcionarios burlen las reglas y las prioridades ${ }^{122}$ para favorecer a determinados expedientes. Este favoritismo ya no se admite por haberse ejercido en aras del beneficio de los funcionarios. El artículo 27 del Código de conducta elaborado por el Consejo de Europa indica a este respecto que "Ios agentes públicos no deben dar un tratamiento diferencial y conceder un acceso privilegiado a antiguos agentes públicos"123.

\section{La sanción de la falta de objetividad por parte de los órganos supervisores}

La falta de objetividad se puede penalizar por las dos vías clásicas de los órganos supervisores de la acción administrativa, a saber: el contencioso de la legalidad y el de la responsabilidad.

\subsection{La anulación de los actos administrativos por falta de objetividad}

Varias disposiciones de diversos textos vinculan expresamente el incumplimiento del principio de imparcialidad y la ilegalidad del acto. Es el caso de los miembros de las comisiones administrativas con carácter consultivo que no pueden tomar parte en las deliberaciones cuando tienen un interés personal en el asunto que se debate, so pena de nulidad de la decisión adoptada tras dichas deliberaciones cuando no se pueda determinar que la participación del miembro interesado o de los miembros interesados no haya influido en la deliberación. Además, una federación deportiva comete una ilegalidad confiando la presidencia de la comisión nacional disciplinaria al que haya denunciado a la persona demandada y que haya pedido a la federación entablar procedimientos disciplinarios ${ }^{124}$.

No obstante, de la jurisprudencia sobre esta cuestión se deduce que los intereses demasiado generales, demasiado indirectos o de intensidad demasiado débil se neutralizan. Por esta razón, la existencia de vínculos de parentesco con los beneficiarios de un determinado acto no es motivo suficiente para determinar que exista un interés ${ }^{125}$, salvo que sea lo suficientemente directo ${ }^{126}$. Por otra parte, un acto solamente se puede juzgar ilegal en la medida en la que la participación de la persona interesada haya tenido una influencia decisiva ${ }^{127}$ en el resultado.

122 CE del 5 de enero de 2005 Gaudeau, req. n. 256653.

123 Recom. del Comité de ministros, Consejo de Europa, n. ${ }^{\circ} \mathrm{R}(2000) 10$, Código de conducta para los agentes públicos, del 11 de mayo de 2000.

124 CE del 30 de noviembre de 2004, Bonnet, req. n. ${ }^{\circ} 136539$.

125 CE del 12 de febrero de 1986, Commune d'Ota, req. n. 45146.

126 CE del 23 de febrero de 1990, Commune de Plougernevel c. Lenoir et autres, req. n. ${ }^{\circ} 78130$.

127 No caracteriza esta influencia decisiva el caso en que el órgano deliberado se pronuncie por unanimidad y el interesado no haya desempeñado un papel central, en tanto que relator principalmente: CE del 26 de febrero de 1982, Association renaissance d'Uzès, req. n. ${ }^{\circ} 12440$. 
La falta de objetividad puede ser fuente de desviación de poder. Cuando el Consejo de Estado anula, por este medio, una ordenanza del alcalde que atañe a los cuerpos de la policía porque se ha basado en la preocupación por proteger los intereses de determinados comerciantes de la localidad, censura así la falta de imparcialidad ${ }^{128}$. De igual modo, en un contencioso relativo al plan de ocupación de suelos, la desviación de poder permite sancionar decisiones parciales: las modificaciones precipitadas de este documento entre la publicación y la aprobación del mismo pueden llevar a pensar en la existencia de intenciones culpables ${ }^{129}$.

\subsection{El compromiso de la responsabilidad de los funcionarios por falta de objetividad}

Basándose en el artículo 15 de la Declaración de los derechos del hombre y del ciudadano del 26 de agosto de 1789, en virtud del cual "la Sociedad tiene derecho de pedir cuentas a cualquier agente público de su administración”, la responsabilidad de los funcionarios se puede exigir en un terreno civil, disciplinario o penal.

La responsabilidad civil suele identificarse con la responsabilidad de los agentes por faltas personales. La parcialidad se considera, en efecto, una falta personal, es decir, según los términos de Laferrière, que "hace aparecer al hombre con sus debilidades, sus pasiones y sus imprudencias". La falta se comete en el ejercicio de las funciones, pero se desvincula intelectualmente por las intenciones subyacentes o por el carácter excesivo del comportamiento, como la calumnia, la injuria o la denigración ${ }^{130}$. También pueden darse faltas personales desprovistas de un vínculo con éste: es el caso que se presenta cuando un funcionario utiliza información en beneficio propio o de un tercero. Según una jurisprudencia secular, la manifestación de sus convicciones religiosas por parte de un agente en el marco del servicio constituye asimismo una falta personal y no una falta de servicio ${ }^{131}$.

La responsabilidad disciplinar -que, en el tema que nos ocupa, tiene más que ver con una represión disciplinar- puede concernir a un funcionario que, por su comportamiento, pudiese haber parecido no ser suficientemente objetivo. Cuando los funcionarios desatienden su obligación de objetividad se ven expuestos a sanciones disciplinarias. El artículo 29 de la ley del 13 de julio de 1983 relativa al estatuto general de los funcionarios dispone que "toda falta cometida por un funcionario en el ejercicio o

128 CE del 25 de enero de 1991, Brasseur. En este sentido M. Degoffe, “L'impartialité de la décision administrative", RFDA 1998, p. 722.

129 CE del 3 de abril de 1987, Commune de Viry-Châtillon, LPA del 22 de abril de 1988, p. 10, nota de F. Moderne.

130 Véase respectivamente TC del 12 de junio de 1961, Picot, Rec. 973 ; TC del 26 de octubre de 1981, Préfet des Bouches-du-Rhône, Rec. 657 ; TC del 17 de julio de 1952, Parray, Rec. 639 ; TC del 26 de octubre de 1981, Préfet des Bouches-du-Rhône, Rec. 657.

131 TC del 2 de junio de 1908, Girodet c. Morizot, Rec. 597, concl. Tardieu: propósitos blasfemos y obscenos de un docente ante sus alumnos. 
con motivo del ejercicio de sus funciones lo expone a una sanción disciplinaria sin perjuicio, en su caso, de la aplicación de las penas previstas en derecho penal". Cabe destacar que no existe definición legal de la falta disciplinaria; sin embargo, esta ausencia de principio de legalidad de las infracciones en materia disciplinar se ve compensada por el control normal sobre la cualificación de la falta disciplinaria que ejercen los jueces administrativos.

A modo de ejemplo, en caso de inobservancia del principio de laicidad, los agentes se pueden ver castigados con una sanción disciplinaria que va hasta la revocación de su cargo ${ }^{132}$. Además, si se trata de un agente con una relación contractual, este tipo de incumplimientos puede implicar la no renovación de su contrato ${ }^{133}$. Así mismo, que una agente con una relación contractual de derecho público se niegue, durante el ejercicio de sus funciones, a retirar el velo religioso que lleva, constituye una falta grave que puede justificar su despido por motivos disciplinarios, incluso estando embarazada ${ }^{134}$. También se puede despedir, sin previo aviso y sin derecho a percibir indemnización alguna a tal efecto, a una asistente materna con una relación contractual, colegiada por los poderes públicos, que lleve el velo cuando acompañe a los niños que cuida a la consulta médica pública que organiza todos los meses la guardería infantil ${ }^{135}$ en la que trabaja.

Por último, se puede investigar la responsabilidad penal de los agentes públicos. Aunque no encontremos hoy en día ningún rastro en el código penal de sanciones por la falta estricta de objetividad de los funcionarios, existen numerosas disposiciones del código que sancionan comportamientos en los que se puede observar una falta de objetividad de los funcionarios. De este modo, se incrimina la concusión, la corrupción pasiva, el tráfico de influencias, las asunciones de interés ilegales y de participación en las empresas... Y por no tomar tan solo este ejemplo, el delito de asunción ilegal de intereses, anteriormente conocido como delito de injerencia, traiciona la parcialidad -consiste en que un agente con autoridad se aproveche de una empresa a su cargo: muestra de falta de objetividad. Así, el inspector de impuestos encargado de realizar un control fiscal que se propone como asesor de su cliente para ayudarle a obtener un alivio impositivo comete este tipo de delito y, por ello, infringe el principio de imparcialidad ${ }^{136} y$, por tanto, incumple el requisito de objetividad.

El principio de objetividad, apoyándose en principios establecidos más sólidamente en el derecho administrativo francés, se construye lentamente en contacto con los derechos administrativos europeos $\mathrm{y}$, a pesar de que se ha consagrado poco formalmente, inspira materialmente al derecho de acción administrativa.

132 CAA de Versailles del 14 de abril de 2008, n. 06VE01149, Jacqueline H. c. Centre acceuil et soins hospitalier Nanterre, AJFP sept. 2008, p. 255.

133 TA de París del 17 de octubre de 2002, n. 0101740/5, JCP A 2002, 1150, nota de D. Jean-Pierre.

134 CAA de Versailles del 23 de febrero de 2006, n. 04 VE03227, Rachida E. c. Commune de Guyancourt, JCP A. 2006, 1165, cron. J. Grand d'Esnon.

135 TA de París del 22 de febrero de 2007, n. $0415268-5-2$, B, AJFP de julio de 2007, p. 208.

136 Cas. crim. del 3 de abril de 1991, X.., D. 1992, JP p. 225, nota de C. Pagnon. 


\section{BIBLIOGRAFÍA}

\section{Obras}

R. Catherine, Le fonctionnaire français. Introduction à la déontologie de la fonction publique, Sirey, 1973.

F. Chambon y O. Gaspon, La déontologie administrative, LGDJ, col. Systèmes, 1997

D. Jean-Pierre, L'éthique du fonctionnaire civil. Son contrôle par les juridictions administrative et constitutionnelle françaises, LGDJ, 1999.

D. Jean-Pierre, La déontologie de l'administration, PUF, col. Que sais-je ?, 1999.

V. Kondilys, Le principe de neutralité dans la fonction publique, LGDJ, 1994.

C. Vigouroux, Déontologie des fonctions publiques, Dalloz, 2006.

\section{Artículos}

M. Degoffe, “L'impartialité de la décision administrative”, RFDA 1998, p. 711.

N. Kada, "Service public et religion: du renouveau du principe de neutralité" AJFP 2004, p. 249.

G. Koubi, "Le principe de neutralité des services publics: un principe corollaire à la modernisation de l'Etat?", Revue administrative 1992, p. 492.

A. Louvaris, “L'application du principe de neutralité par l'Administration”, Cahiers de la fonction publique, noviembre de 2002, p. 8.

E. Mitard, “L'impartialité administrative”, AJDA 1999, p. 478. 
